larvae of Microdon mutabilis were completely ignored by the ants in a mixed colony of Formica sanguinea-fusca. But he observed that the fly, which is covered with delicate yellow pile, was assiduously licked by $F$. sanguinea although it soon died. Except for this last observation, which relates only to its imaginal stage, Microdon may be regarded as belonging to Wasmann's category of synoeketic myrmecophiles, or indifferently tolerated guests, a great company which also comprises the tiny crickets of the genus Myrmecophila.*

The imagines of a number of species of Microdon have been described from
North America but they all appear to be rare insects. They fly reluctantly and are fond of lurking about the roots of grasses and other plants in situations where they readily elude the observation of the most careful collector. I am unable to conjecture to which of the described Mexican species the larva observed in the Pseudomyrma nests belongs. The accompanying photograph will enable any future observer to identify it without much difficulty, even if it should be found, as I have no doubt it will be, in the nests of other species of ants in Mexico and Central America.

\title{
NOTES ON THE MATING OF ATTACUS CECROPIA AND OTHERS.
}

BY CAROLINE G. SOULE, BROOKLINE, MASS.

In most of the large collections of cecropia cocoons which I have examined the female pupae have outnumbered the male by about five to one, twice by three to one. For this reason I have inferred that the males were polygamous, and this spring I have tested them, as the moths emerged very early.

Close observation has convinced me that the female cecropia requires sixteen hours out of the cocoon before she is ready to mate. In no instance $\operatorname{did}$ a female protrude the whole ovipositor

\footnotetext{
*See Wheeler, The Habits of Myrmecophila nebrascensis Bruner. Psyche, Oct., 1900. pp. I1I-II5; and Wasmann, Zur Lebensweise der Ameisengrillen (Myrmecophila). Natur u. Offenbarung. 47. Bd. Igor pp. I29-152).
}

sooner, and in no instance did the male in the cage with her attempt mating or seem in the least attracted or excited before the protrusion of the whole ovipositor. Partial protrusion occurs earlier.

I feel convinced that there is a different odor diffused when the whole ovipositor is protruded, in the case of all the large Saturniids, and often I think I can detect it in spite of the previous powerful odor of both male and female.

With one exception no female flew or moved about the cage after her wings were expanded until mating had taken place, nor did any female show the least sign of noticing the male or of preference 
for any male except in one other instance when the female vibrated her wings rapidly after the male had been flying about her for nearly an hour.

The first exception was a female which began flying about a male trying to mate, but for some reason none of three males mated her.

One pair mated at midnight, but no others mated before four A. M., though the males' flying and quivering began sometimes an hour earlier, sometimes less.

Eleven males mated, remained in coition for about sixteen hours, then mated a second female each about eight hours later. No male mated a female which had been mated before, - of this set. One male mated the same female on two successive mornings, she having laid over one hundred eggs in the interval. The male then mated a second female on the next morning, but coition lasted only about eight hours. On the next morning the male mated a third female and remained in coition until near midnight.

The following morning the male mated a fourth female, coition lasting sixteen hours, and this female he mated again the next morning although a fresh one was put in the cage. Coition lasted about sixteen hours the second time also.

The next morning the male mated a fifth female, coition lasting from about 4 a. m. till $7.25 \mathrm{p}$. m. when the female freed herself by violent struggles. The male was flying about the sixth female within five minutes, and after fifteen minutes of displaying his wings, flying, and quivering, settled down into quiet for the night. At precisely $4 \mathrm{a}$. $\mathrm{m}$. the male mated the sixth female with no preliminary flight or display except that of the previous evening.

The hour of mating was very near 4 a. $\mathrm{m}$. in every instance, never later than 4.30 .

No new female emerged and the next day passed without mating, but on the following morning the male mated the 6th female for the second time. She resisted vigorously and coition was short.

The next day there was no coition there being no fresh female, and the male died, having mated nine times in thirteen days.

The eleven males which mated two females each had no opportunity of mating others as no other females emerged in time. It seems fair to believe that the male cecropia is very polygamous.

Three males were in boxes with lace over the tops, and so placed that they could not see the female in the cage. They were perfectly quiet until the female protruded the whole ovipositor when, in less than two minutes, they were flying excitedly about the boxes, stopping only when the female mated with the male in the cage.

From observations with promethct angulifera, and cecropia it seems th..1 there is some emanation from the cripositor which attracts the male, and that no male will mate or approach a 
female without being attracted in this way.

Females of Samia cynthia do not protrude the ovipositor as much as do the other Attacine moths, and are far less passive, flying about in as much excitement as the males, and vibrating their wings faster and faster when not flying, quivering all over, and waving their wings in a peculiar manner.

\title{
LIFE HISTORIES OF NORTH AMERICAN GEOMETRIDAE. - XXIII
}

\author{
BY HARRISON G. DYAR, WASHINGTON, D. C.
}

Xanthotype crocataria Fab. The larva and pupa of this species have been described by Packard, Bowles, French and Forbes, but no complete life-history has been given.

E gg. Laid in patches of six to twenty. Elliptical, flattened, concave on two sides but rounded, wedge shaped from side view, the thick end flattened, subtruncate; shagreened by a minute granulation and with traces of hexagonal reticulations which are indicated only, chiefly by the minute bordering pores which appear as white specks in certain lights. Shining light green. Size $.7 \times .5$ $\times .3 \mathrm{~mm}$. Later turning rather dark red.

Stage I. Head rounded, slightly bilobed, pale brownish ocherous, a narrow dark line on the posterior angles, not shining, ocelli black; width $.3 \mathrm{~mm}$. Body moderate, normal; white, subdorsal and medioventral purple-brown bands, moderate, straight, reaching from joint 2 to $I_{3}$, the subdorsals a little divergent on joints 2 and $\mathbf{r}_{3}$. Tubercles and setae minute, dark, inconspicuous. Feet pale outwardly; segments faintly annulate, uniform, incisures not marked. Shields concolorous, not cornified. On eating, the color became greenish from the food showing by transparency.

Stage II. Head erect, rather higher than wide but not above joint 2, pale luteous with a blackish stripe on each side across ocelli to near vertex, behind which the color is whitish; width $.55 \mathrm{~mm}$. Body normal, a little flattened. Dorsum whitish green, a broad red-brown subdorsal stripe, divergent on joints 2 and $\mathrm{I} 3$ to the anal feet; sides green, whitish on subventral fold; a ventral stripe like the subdorsal but single, reaching from the head to joint I3. Feet pale; skin smooth.

Stage III. Head rounded, somewhat flattened before and held obliquely flat; pale greenish, obscurely white streaked vertically, the rather large antennae and a stripe on the sides bearing ocelli white, the stripe faintly dark edged before; ocelli black; width 9 $\mathrm{mm}$. Body moderate, normal, a little flattened; anal plate slightly pointed, anal feet triangular, excavate behind with anal prongs which equal the plate. Light green, four white lines in the dorsum; a subdorsal (or rather lateral) band of smoky brown, fainter than before; a greenish white stripe on the subventral fold; subventer faintly white lined, the brown ventral stripe like the subdorsal in color. Feet pale, tubercles and setae small.

Stage IV. Head rounded, squarish, flattened but convex in front, antennae large; held out quite flat; whitish with green tint, obscurely mottled brighter on the sides, a blackish band on the lateral angle forming a bend at antennae to mouth, crossing ocelli ; 

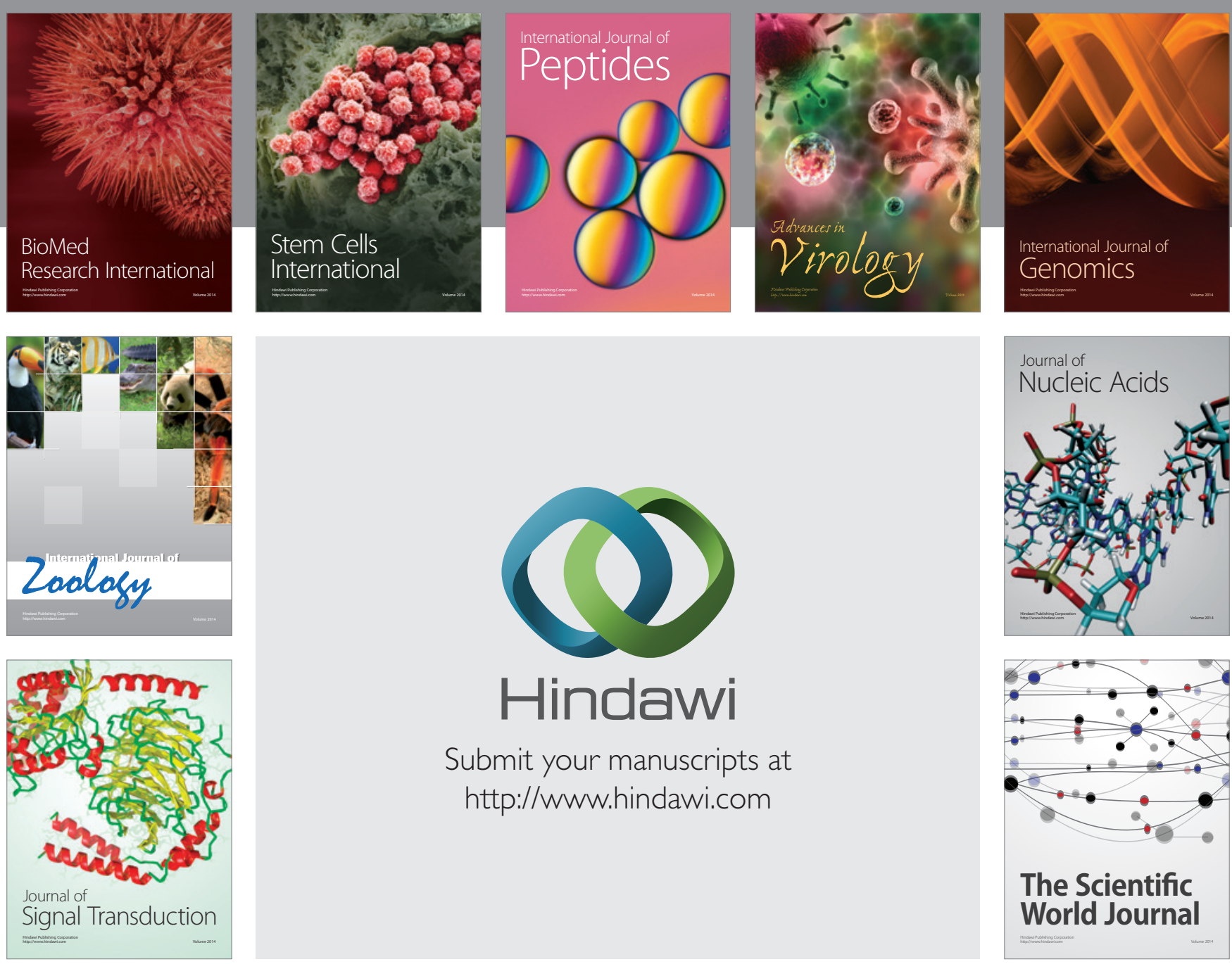

Submit your manuscripts at

http://www.hindawi.com
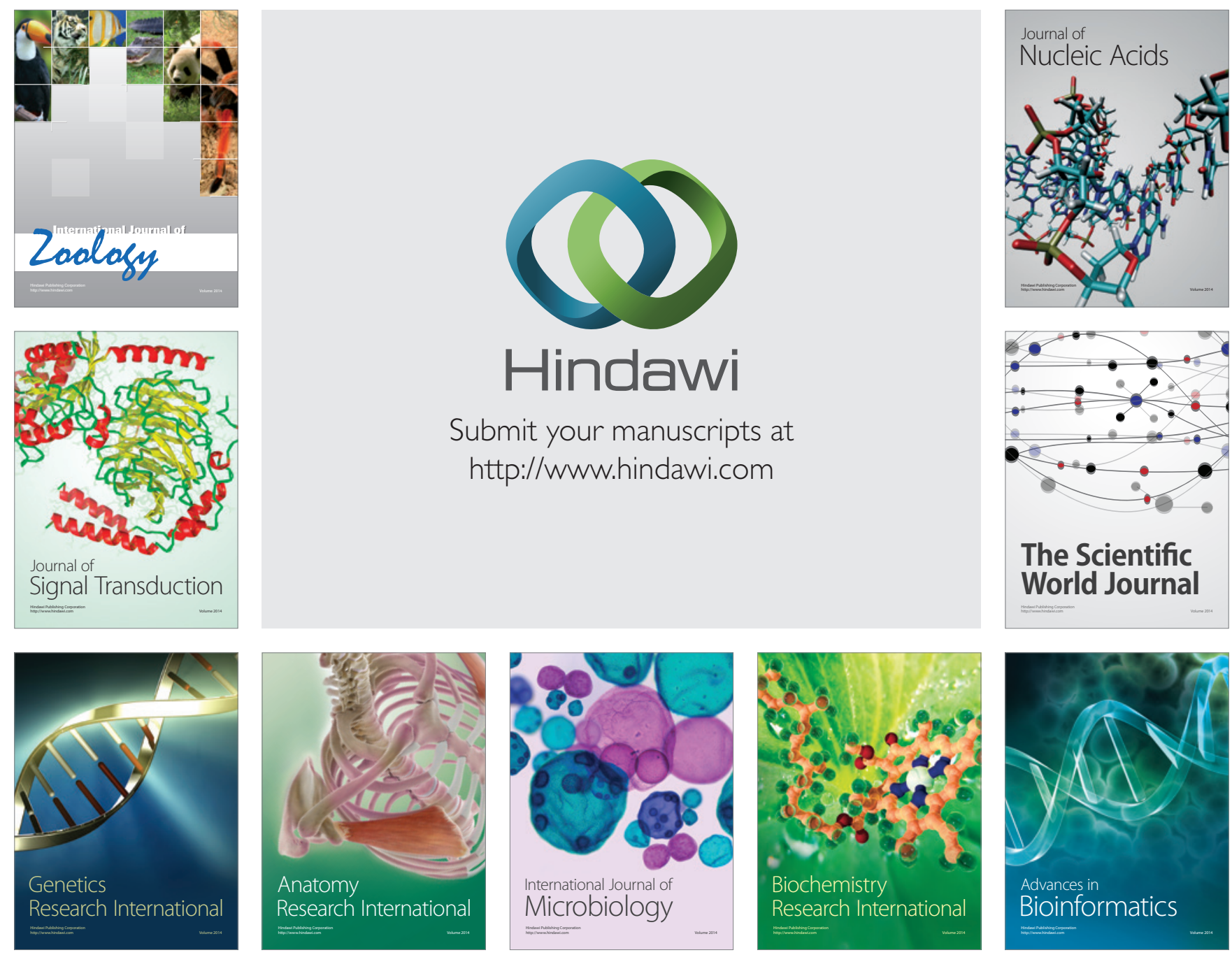

The Scientific World Journal
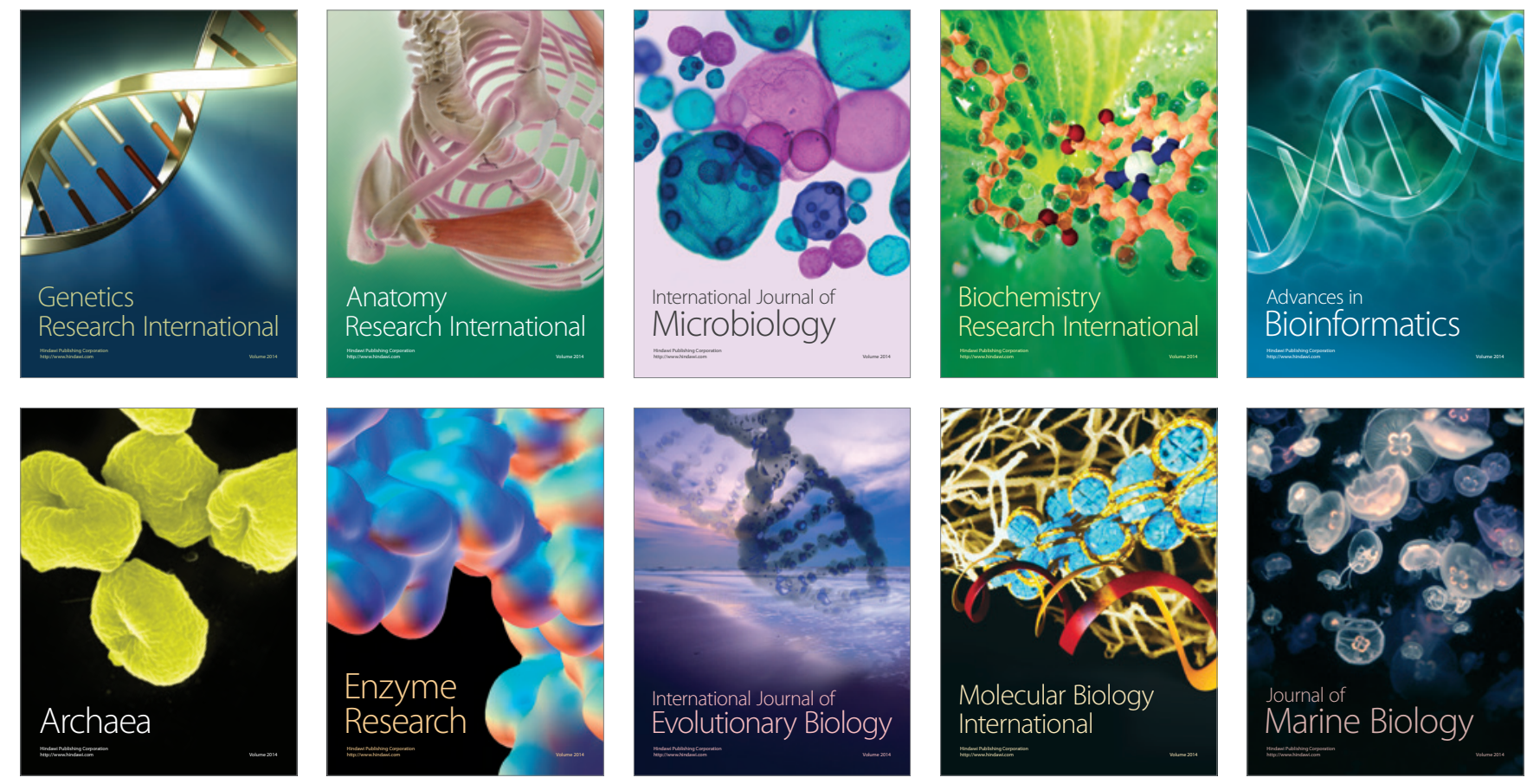